\title{
Relationship between vegetation growth rates at the onset of the wet season and soil type in the Sahel of Burkina Faso: implications for resource utilisation at large scales
}

\author{
Lalit Kumar a,b,*, Max Rietkerk a, Frank van Langevelde a, \\ Johan van de Koppel ${ }^{\text {a,c }}$, Jelte van Andel ${ }^{\mathrm{d}}$, John Hearne ${ }^{\mathrm{e}}$, Nico de Ridder ${ }^{\mathrm{f}}$, \\ Leo Stroosnijder ${ }^{\mathrm{g}}$, Andrew K. Skidmore ${ }^{\mathrm{b}}$, Herbert H.T. Prins ${ }^{\mathrm{a}}$ \\ a Department of Environmental Sciences, Tropical Nature Conservation and Vertebrate Ecology Group, Wageningen University, \\ Bornsesteeg 69, 6708 PD Wageningen, The Netherlands \\ ${ }^{\mathrm{b}}$ International Institute for Aerospace Survey and Earth Sciences (ITC), Agriculture, Conservation and Environment Division, \\ P.O. Box 6, 7500 AA Enschede, The Netherlands \\ ${ }^{\mathrm{C}}$ International Institute for Infrastructural, Hydraulic and Environmental Engineering (IHE), P.O. Box 3015, \\ 2601 DA Delft, The Netherlands \\ ${ }^{\mathrm{d}}$ Department of Plant Biology, University of Groningen, P.O. Box 14, 9750 AA Haren, The Netherlands

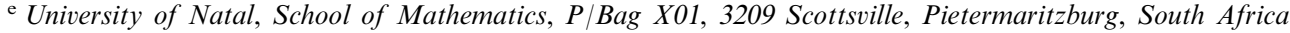 \\ ${ }^{\mathrm{f}}$ Department of Plant Sciences, Plant Production Systems, Wageningen University, P.O. Box 430, 6700 AK Wageningen, \\ The Netherlands \\ ${ }^{g}$ Department of Environmental Sciences, Erosion and Soil and Water Conservation Group, Wageningen University, \\ Nieuwe Kanaal 11, 6709 PA Wageningen, The Netherlands
}

\begin{abstract}
In the Sahel, poor soil quality and rainfall levels have a great influence on pasture production and hence on secondary output. In areas where rainfall is the limiting factor for primary production, recovery of primary and secondary production after the dry season depends on soil type. On sandy soils a large fraction of rainfall infiltrates and becomes available for plant growth, stimulating fast herbage growth, while on clayey and loamy soils low infiltration rates generate runoff, leading to slower herbage growth rates. The very different moisture retention characteristic of sands and clays is another possible cause for the observed differences in growth rates. In this paper we investigate the herbage growth rate from the onset of the rainy season. We hypothesise that, in areas where rainfall is the limiting factor for primary production, the vegetation growth rate on clayey soils is lower than that on sandy soils. We will test this hypothesis using long-term rainfall, soil types and satellite derived normalised difference vegetation index data. This research shows that the growth rates on sandy soil are significantly greater than that on clayey soils during the early part of the rainy season. We also show that these differences can be detected at large scales using satellite imagery. We also conclude that, at this scale, movement strategies of pastoralists would be
\end{abstract}

* Corresponding author. Tel.: + 31-53-487-4472; fax: + 31-53-487-4388.

E-mail address: kumar@itc.nl (L. Kumar). 
intrinsically linked to not only rainfall patterns and distribution, but also to the underlying soil types in the region as this affects the quality and quantity of fodder available. (C) 2002 Elsevier Science B.V. All rights reserved.

Keywords: Herbage growth; Soil hydrology; Semi-arid grazing systems; Remote sensing; NOAA-AVHRR; Normalised difference vegetation index

\section{Introduction}

While the Sahel is relatively sparsely populated, it normally offers good rainy-season grazing to huge herds of cattle, camel, goats and sheep. The area is mainly utilised by transhumant pastoral groups such as the Maur, the Tuareg, the Songhaï, and the Fulani. In Burkina Faso, these groups move north into the Sahelian zone during the rainy season and travel back south to the fringes of the Sahelian zone at the end of the wet season as the northern parts cannot sustain the animal population during the dry parts of the year and also due to the attraction of crop residues in the southern regions.

The planning and time selections for movement up north are crucial as a wrong decision can have devastating effects on the herds. Departing too early entails the risk that there will not be enough water and suitable pasture available for the animals, while leaving it till too late means that there will be increased competition for resources at their semi-permanent place in the south as most of the grazing land will now be utilised for agriculture.

With the arrival of the seasonal rains the barren areas of the north are transformed into good grazing lands, but this transformation is neither homogenous nor all at the same time. The vegetation comes up in patches; a result of many different factors. Some of these include soil type, nutrient availability, terrain, etc. (Breman et al., 1991). In the absence of advanced technology and prior knowledge as to which areas have the best vegetation, the herdsmen depend on word of mouth or past experience to decide exactly when to start their journeys and which routes to take (Ruttan and Borgerhoff Mulder, 1999; de Boer and Prins, 1989). A better understanding of the vegetation recovery patterns in these areas will help us gain better insights into how the pastoralists of the region plan and time their journeys and will also aid in modelling these complex systems.
Remote sensing is a common technique used to gather information relating to primary production over a period of time. The green leaf biomass or intercepted photosynthetically active radiation (PAR) of plant canopies can be non-destructively estimated using the red and near-infrared channels of remote sensing sensors such as NOAAAVHRR and Landsat (Tucker, 1979, 1980; Curran, 1980). Indices such as the normalised difference vegetation index (NDVI) can be used to estimate primary production, as there is a high correlation between these 'greenness' indices and the intercepted PAR. One of the advantages of using satellite remote sensing to estimate primary production is that large areas can be measured directly and that the biomass integrates many biotic and abiotic variables affecting primary production (Tucker et al., 1985).

In this paper we investigate the rate of increase in vegetation biomass on sandy and clay soils from the onset of the rainy season, by using NDVI data derived from the NOAA-AVHRR sensors. We hypothesise that, in areas where rainfall is the limiting factor for primary production, the rate of increase in vegetation biomass on clayey soils is lower than that on sandy soils. The reasoning behind this is that if there is limited rainfall then vegetation on sandy soil will have an advantage over that on clayey soils as whatever little rain falls on sandy soil will infiltrate and be available for plant use, while of this same rain falling on clay soils, only a small fraction will infiltrate and be available for plant use. The major portion will be redistributed through runoff or lost through evaporation. Differences in water holding capacity between the two soils is also an important contributing factor. We also study the time lag between biomass on sandy soil and that on clayey soil; i.e. the time it takes vegetation on clayey soils to reach the same levels to that on sandy soils. We then discuss the implications of these differences in 
vegetation growth rates and time lag on decisions taken by herdsmen in relation to planning their migration into the Sahel region at the start of the rainy season.

\section{Method}

\subsection{Study area}

The study was carried out in the Sahelian (northern) zone of Burkina Faso (West Africa). This area is predominantly used for grazing, although some agricultural intrusion is taking place. The region has clearly defined seasons, with a short monomodal rainy season lasting 2-3 months (July-September), and a long dry season. Mean annual rainfall (averaged over the years 1960-1999) is from 350 to $500 \mathrm{~mm}$ as a range over the $\mathrm{N}-\mathrm{S}$ Sahel. The region also has very high evapotranspiration rates. Mean monthly temperature ranges between $21{ }^{\circ} \mathrm{C}$ in January to $35{ }^{\circ} \mathrm{C}$ in May, with maximum temperatures of well over $40{ }^{\circ} \mathrm{C}$. The Sahelian zone represents about $25 \%$ of the country's surface area and is the driest climatic region of Burkina Faso. The region has a population density ranging from 15 inhabitants per square kilometre in the north to about 50 inhabitants per square kilometre in the southern Sahelian zone (based on 1996 census data).

This region was selected for the study as it is mainly used by pastoralists (transhumance system) and the rainfall is in the range where water becomes the limiting factor for vegetation growth (Breman and de Wit, 1983).

\subsection{Data}

Biomass information was obtained by using the maximum-value-composite (MVC) NDVI images derived from the NOAA series of satellites. An MVC image groups data that are collected daily into 10-day periods (dekad) and each pixel is assigned the maximum value over the dekad (Holben, 1986). The resolution of the images was 7 by $7 \mathrm{~km}$. While this is fairly coarse, it is the only data available on a time series basis over a long period of time. MVC images for every dekad over an 18-year period (1982-1998) were stored in a GIS database. The data for 1990 was not used in the analysis due to problems with some of the images. A 1:500 000 soil map (Boulet and Leprun, 1976) of the area was digitised and regions with predominantly clay and sandy soil were selected. This data layer was then used to extract NDVI values from the MVC images and for the correlations.

\subsection{Correcting for differences in soil background reflectance}

For a vegetation canopy on a rangeland soil surface the incoming solar radiation interacts with the vegetation canopy and also, depending on the actual amount of cover, interacts with the background. Different soils will have different reflectance signatures, therefore similar cover on two different soil types do not produce the same reflectance value. To compare vegetation recovery rates, differences in background reflectance are corrected by assuming that at the end of the dry season the region was devoid of any vegetation and therefore any differences in reflectance values were caused by differences in soil reflectance properties. This is a valid assumption for the region studied as, for Northern Burkina Faso, the only green vegetation left at the end of the dry season is some shrubs and a few trees, hence reflectance differences can confidently be attributed to differences in soil reflectance properties. ${ }^{1}$ So, to correct for these differences, the difference in NDVI value between sandy soil and clay soil lines at the end of the dry season was subtracted from all subsequent values of sandy soil NDVI's. The result was that the sandy soil line was displaced downwards to coincide with the clay soil vegetation line at the beginning of the rainy season. A somewhat different method may have been to use the PD54 index (Pickup et al., 1993), which rather than subtracting a fixed value from all post-drought NDVI values, takes into account the changing vegetation and how this may affect reflectances from different surfaces.

\footnotetext{
${ }^{1}$ We would like to add that soil reflectance also varies by degree of wetness, and since this is almost impossible to monitor for the multi-year analysis reported here, the method used is the best available alternative.
} 
The use of this method would result in slightly greater differences than that observed here for the later part of the rainy season. However, it would have very little effect for the early part of the rainy season when there is much less vegetation, and since we were interested in the vegetation growth (as opposed to identification or mapping) for the early part of the rainy season, we do not expect any difference in the results between the two methods.

\subsection{Correcting for differences in start of rainy season}

In order to make between-year comparisons one has to take into account that the rainy season does not start on the same date every year, so for example the NDVI value for a given day of one year cannot be compared with the value of the same day the following year. We normalised this by taking the start of the rainy season as the first dekad for all years. To decide when the rainy season starts each year, we used cumulative rainfall values and declared the rainy season date to start when the cumulative rainfall exceeded 20 $\mathrm{mm}$. This was based partly on the findings of Prins (1988), who reported that the perennials started responding when rainfall exceeded $20 \mathrm{~mm}$. Preliminary investigation of the NDVI images showed that there was no noticeable change in NDVI values with cumulative rainfall being less than $20 \mathrm{~mm}$, indicating that even the annuals were not responding significantly to rainfalls below this level.

\subsection{Removal of agricultural zones}

To compare the vegetation recovery rates, it was also necessary to identify those areas used for cultivation and remove them from the selection. This was necessary as cultivated areas have a better plant growth rate since the land is tilled (which increases water infiltration rates) and manure or fertilisers are applied. The overall vegetation recovery rates would be affected based on whether more of clay or sandy soil was under cultivation.
Using remote sensing images, areas under cultivation can be identified on the basis of the rate at which their NDVI values change. In Northern Burkina Faso, the major agricultural crops are millet and sorghum. During harvest, most of the stalk is either used as fodder for the animals or for making walls and roofs for the houses. Hence during the harvest period, the areas under cultivation are transformed into barren earth in a matter of days. This change can easily be detected using time series remote sensing data, in that the NDVI values decrease very quickly in a short time period when compared to non-agricultural areas. For this exercise we used the rule that there should be a consistent decline of $20 \%$ in the NDVI values for every dekad over 3 dekads during the harvesting season before an area was declared to have been under cultivation. Sensitivity analysis showed that using values between $15-25 \%$ returned similar results, so a value of $20 \%$ is not critical.

\subsection{Statistical analysis}

To test whether the vegetation lines of the two soil types had significantly different slopes, we used the multiple regression analysis (GLM) with NDVI as the dependent variable, soil type as the fixed variable and time as the covariate. The data for the eighteen years were grouped together. We also calculated the differences between the NDVI values for both soil types at each dekad and used Spearman's correlation to check whether these differences were correlated with either cumulative rainfall or time from the beginning of the rainy season. A strong correlation would show that the difference between the vegetation biomass on the two soil types increases with time, and would confirm our hypothesis that the two soil types have different vegetation growth rates. Alternately, a weak or no correlation would suggest that the recovery rates on both the soil types are similar.

The lag times were calculated as the averages of lags at dekad 3, 4, 5 and 6 (in the mid-growing season) from the beginning of the rainy season. Fig. 1 gives a general representation of lag between clay and sandy soils. 
The annual rainfall patterns were also analysed and negatively and positively skewed rainfall distribution years were separated and the vegetation

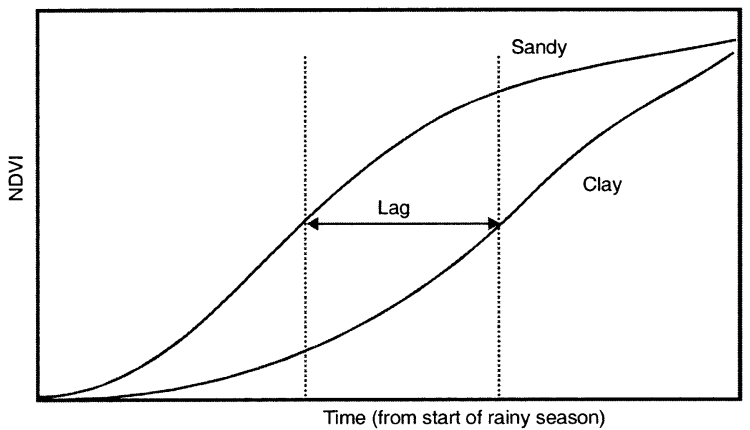

Fig. 1. Representation of lag between NDVI levels on clay and sandy soils. The lag was taken as the average of the lags at dekad 3, 4, 5 and 6 from the beginning of the rainy season.

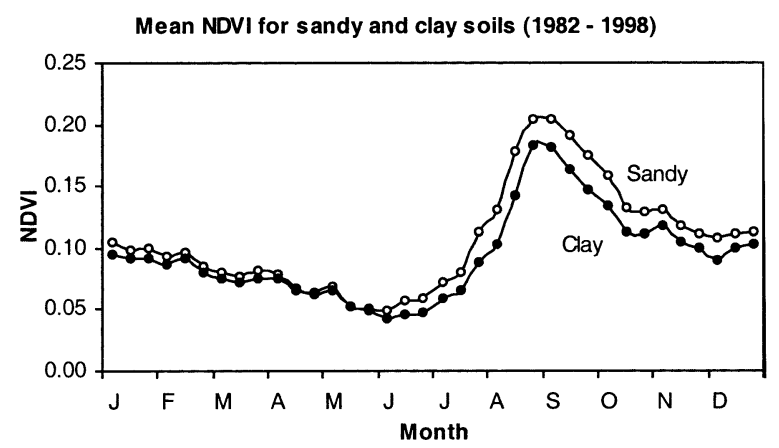

Fig. 2. Average NDVI levels on sandy and clay soils after correction for background reflectances.

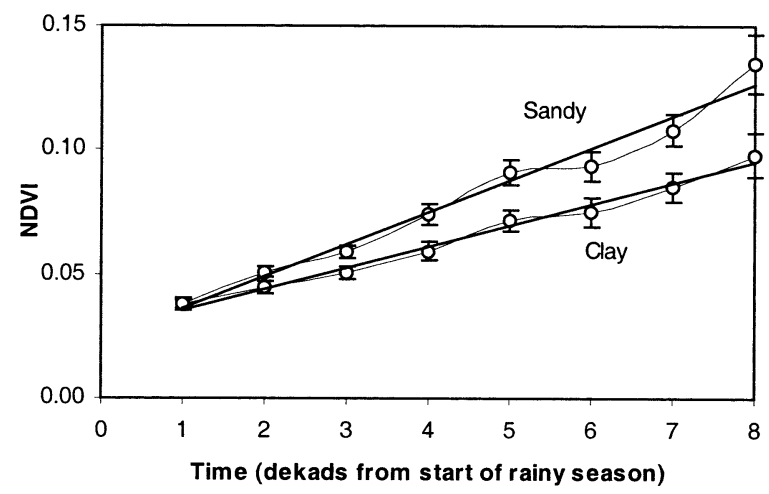

Fig. 3. The rate of change in NDVI (vegetation recovery) during the main growing season (error bars show standard errors of mean, $n=18$ ). growth rates for these two sets were also compared using the methods as described above.

\section{Results}

\subsection{Rate of increase in NDVI derived index}

When long-term data (data over 18 years) are grouped together, it is clearly seen that the average NDVI on sandy soils is consistently greater than that on clayey soils (Fig. 2). This is especially true for the rainy and the early part of the dry season, where the NDVI level for sandy soil is always above the clay soil NDVI level. The differences are greatest around eight to ten weeks after the start of the rainy season, and occur before maximum NDVI levels are reached. During the later part of the dry season (February-May) the NDVI levels are similar on both sandy and clayey soils.

Note that an analysis of the soil map indicated that there was an even distribution of sandy and clay soils over the range of rainfall zones; thus the differences reported here are not due to the possibility of the clay soils being in low rainfall zones and sandy soils being in higher rainfall zones.

For the early growing season (the first two months of the rainy season) the average rate of increase in NDVI on sandy soils is significantly greater than that on clayey soils (Fig. 3). The slope of the NDVI line on sandy soil was found to be significantly different $(P<0.01)$. The slopes were also significantly different when data from the beginning of the rainy season to the maximum NDVI levels were used.

On an annual basis, it was clear that the difference in NDVI levels between the two soil types increased for the first few months of the rainy season and then levels out (Fig. 4); i.e. the rate of change in biomass levels is greatest at the beginning of the rainy season, as depicted by the trend line in Fig. 4. Table 1 shows the results of correlating the difference in NDVI levels for the two soil types with cumulative rainfall for the eighteen years. The second column gives the results where all NDVI values from the beginning of the rainy 


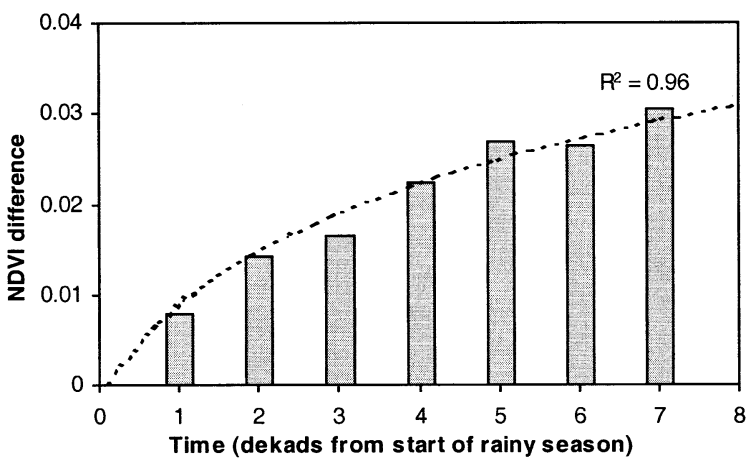

Fig. 4. The difference in NDVI levels between sandy and clay soils increases at the beginning of the rainy season and then levels off. The bars show the absolute difference between the corrected NDVI values of sandy and clay soils, and the dashed line gives the trend.

Table 1

Correlation between difference in NDVI (maximum minus minimum, and during main growing season) and cumulative rainfall

\begin{tabular}{lll}
\hline \multicolumn{3}{c}{ Spearman correlation } \\
\hline & Min -Max NDVI & Main growing season \\
1982 & $0.87^{* *}$ & $0.93^{* *}$ \\
1983 & $0.65^{*}$ & $0.83^{*}$ \\
1984 & $0.70^{*}$ & $0.96^{* *}$ \\
1985 & $0.84^{* *}$ & $0.86^{*}$ \\
1986 & 0.58 & $0.89^{*}$ \\
1987 & $0.87^{* *}$ & $0.75^{*}$ \\
1988 & $0.82^{* *}$ & $1.00^{* *}$ \\
1989 & 0.67 & $0.94^{* *}$ \\
1991 & 0.26 & $0.90^{*}$ \\
1992 & 0.23 & 0.71 \\
1993 & $0.80^{* *}$ & $0.81^{*}$ \\
1994 & $0.78^{*}$ & $0.89^{*}$ \\
1995 & 0.15 & $0.96^{* *}$ \\
1996 & $0.92^{* *}$ & $0.95^{* *}$ \\
1997 & 0.61 & 0.43 \\
1998 & $0.90^{* *}$ & $1.00^{* *}$ \\
\hline
\end{tabular}

$$
* P<0.05 \text {. }
$$$$
\text { ** } P<0.01 \text {. }
$$

season to the time when maximum NDVI is achieved being used for the correlation, while for the last column only the main growing season data (the first eight weeks after the start of the rainy season) are used. The results show that there is a strong correlation between differences in NDVI levels and cumulative rainfall for most of the comparisons. Correlation coefficients are higher when the main growing season data are used.

\subsection{Lag times}

The average lag time in biomass levels between sandy and clay soils was found to be about twelve days. This means that, on average, the levels of biomass on clay soils were about twelve days behind those on sandy soils. The time lag decreased to an average of eight days when the rainfall distribution over the rainy season was normal to positively skewed and increased to approximately 20 days when the rainfall season was negatively skewed.

\section{Discussion}

It has been suggested that environmental processes at large (coarse) scales are to a great degree the result of processes at smaller (fine) scales (Heuvelink, 1998). We believe that the differences in vegetation growth rates at large scales as seen here are the result of several dominant small-scale processes. Research undertaken at small scales have shown that there are large differences in water infiltration rates between sandy and clay soils (Withers and Vipond, 1974; Morgan, 1986; Rietkerk et al., 2000). Our own research within the study region showed that sandy soil had infiltration rates three times higher than clay soil (Rietkerk et al., 2002). The water holding capacities and the water potentials of the two soil types also differ greatly.

For untilled clayey soil regions with low rainfall, the first process (water infiltration rates) dominates and will determine the amount of water available for plant growth. If there is limited rainfall then vegetation on sandy soil will have a distinct advantage to that on clayey soils. This is because rain falling on sandy soil will largely infiltrate and be available for plant growth. On the other hand, of this same rain falling on clay soils, some will infiltrate and be available for plant growth, while a large portion will be lost as either runoff or through evaporation. The differ- 
ences in soil water potential between sandy and clay soils also works against vegetation on clayey soils. Under normal circumstances infiltration rates for sandy soils are much higher than that on clayey soils, but this difference is greatly increased in the Sahel due to the extent and types of crusting present on the two soil types (Graef and Stahr, 2000). Crusting decreases the infiltration rate, reduces the available water at the root zone, increases runoff and soil erosion and affects seedling and plant growth (Mualem and Assouline, 1996). Crusts also appear on sandy soils, based on their clay content, but are different to those on clayey soils (Govers and Poesen, 1985; Mualem and Assouline, 1996). Crust types are correlated with soil texture (Casenave and Valentin, 1989) and each of these crust types have different thickness, strength and porosity (Graef and Stahr, 2000). Hence the differences in infiltration rates are greatly increased and are one of the main reasons why we see such large differences in the vegetation growth rates. A number of studies have identified soil crusting as a major factor decreasing water infiltration capacity and increasing runoff in most areas of the Sahel (Hoogmoed and Stroosnijder, 1984; D'Herbès and Valentin, 1997), which also implies a strong impact on crop yield security and pasture availability. While the work of Hoogmoed and Stroosnijder (1984) dealt with arable soils, our work shows that similar reasoning can be extended to the study of pastoral and natural systems.

The different growth rates and time lag can perhaps be equally well explained by the different amounts of rainfall that is required to bring an air dry sand or clay to a moisture level that allows significant flow in the root zone (i.e. $\mathrm{pF}<4.2$ ). Air dry moisture contents are typically $1-2 \%$ for sands and 5-7\% for clay. Moisture contents at wilting point are typically $2-8 \%$ for sands and can be more than $25 \%$ (or even $30 \%$ ) for clays. For a $50 \mathrm{~cm}$ root zone, this means that plant growth can resume with approximately 20-30 $\mathrm{mm}$ of rainfall for sandy soil, but will require three to four times as much rainfall on clayey soils.

It should be noted that the importance of the two processes discussed, namely infiltration rates and moisture retention characteristics, will differ at different spatial scales. At large (regional) scales, the runoff generated in one part of a pixel is likely to infiltrate elsewhere (foot slopes, streamlines, etc.) within the same unit, and possibly lead to increased plant production for the unit as a whole. At such scales, the observed differences in herbage growth rates are more likely to be due to accumulated soil moisture rather than infiltration capacity. This view is also supported by Nicholson and Lare (1990) and Malo and Nicholson (1990). At smaller (local) scales and in uniform landscapes, differences in water infiltration rates will play a more prominent role.

The results here suggest that the differences in vegetation early growth on different soil types could also determine the strategies adopted by pastoralists during their annual migration from the southern regions to northern areas at the beginning of the rainy season. This annual movement of herds from the south to the north takes place as more areas in the southern regions are used for agriculture (mainly maize and sorghum) and thus the pastoralists are forced to relinquish their dry season grazing grounds. The movement north is in search of better grazing grounds, with better quality pasture and less diseases, and also to avoid competition for limited resources available in the south. The migrations are more proactive than reactive.

At low water availability ((i) low rainfall or (ii) high rainfall but high runoff), growth cycle is shorter than at high water availability (species composition adapt to growing period determined by water availability). Nutrient contents (in particular proteins) in plants decrease during the growth cycle, whereas the lignine content increases. Thus, feed quality decreases during the growth cycle, but at low water availability nutrient concentrations will stay higher during the entire growth period than at high water availability. Fodder availability and quality will thus alternate between sandy and clay soils during the growing season in a given rainfall zone (Breman and de Wit, 1983). At sandy soils vegetation will recover earlier than at clay soils (little but green biomass available at high quality in young plants). At clay soils vegetation will recover later, 
at that time of still high quality but low biomass whereas the vegetation on sandy soils already has developed to higher biomass with lower quality. Thus in time and space livestock may shift from sandy soils to clay soils if the ratio of quantity and quality becomes more favourable on the clay soils compared to the sandy soils.

Based on our results, within a given rainfall zone, we can divide the movement decisions to be made by pastoralists into three zones (Fig. 5). From the beginning of the rainy season to time $T_{1}$, the movement should be towards areas with sandy soil. During this period the direction of movement is dictated by the quantity of vegetation, and since sandy soil regions have greater biomass than clay soil regions, the movement would be directed towards sandy soil areas.

After time $T_{2}$, quantity of vegetation would no longer be an issue as both sandy and clay soil regions have a biomass above a certain threshold level $B_{2}$. Hence after this time period $\left(T_{2}\right)$ quality and digestibility of vegetation rather than quantity of vegetation would dictate the direction of movement. The quality of vegetation also depends on the richness of the underlying soil, and generally the nutrient content of clay soils is better than that of sandy soils; hence one would expect that after $T_{2}$ the movement might be more towards clay soil areas.

Between the time periods $T_{1}$ and $T_{2}$, there is a transition zone where the direction of movement is not dictated by any one factor alone. There would be interplay between quality and quantity of vegetation, as explained earlier.

The above discussion is valid if locations are within a given rainfall zone. For locations that are in different rainfall zones, the movement would first be towards locations in higher rainfall regions and then would be based on soil types as discussed above. It should also be noted that the movement strategies would not only depend on soil types in the surrounding area but also on the pattern of rainfall. If, at the start of the rainy season, rainfall is consistently low then the time taken for vegetation on clay soils to reach the levels to that on sandy soils is longer, so pastoralists would delay going to these regions. On the other hand, if there is good rainfall at the beginning of the season, the lag in vegetation biomass on clay soils is lower, so pastoralists can move to these areas sooner.

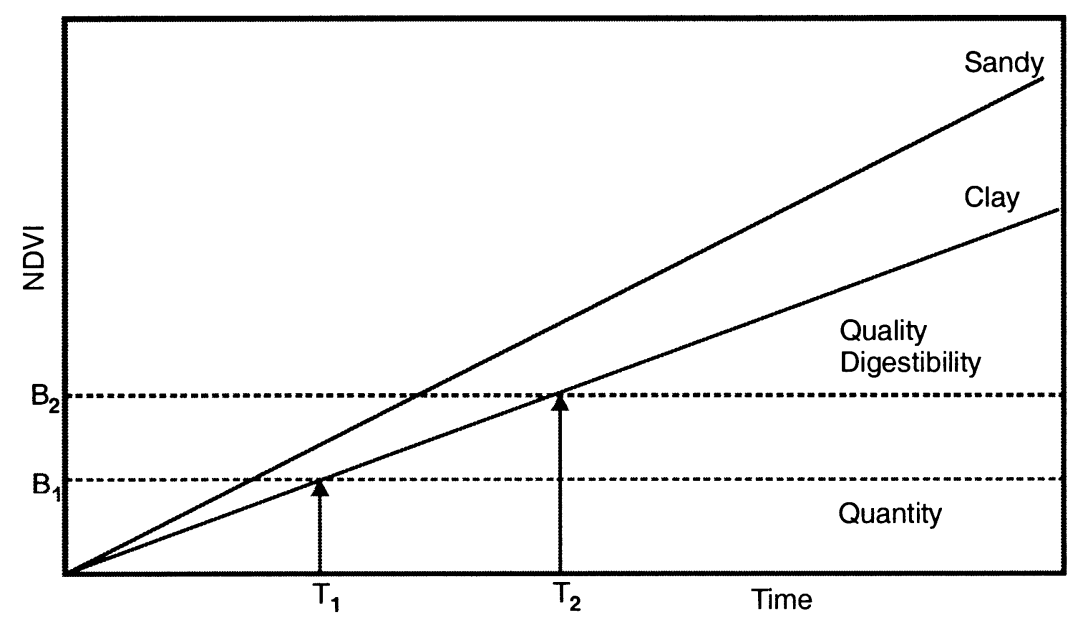

Fig. 5. Time and space zones showing how livestock may shift positions based on differences in quality and quantity of vegetation between regions. From the beginning of the rainy season to time $T_{1}$ quantity of vegetation is the dominant factor, and since sandy soil has more vegetation the movement will be towards zones of sandy soil. After time $T_{2}$ the quality and digestibility of vegetation are the primary factors, and since there is sufficient vegetation on both sandy and clay soils, the movement will be towards zones of clay soils (higher quality vegetation). Note that it is also likely that the sandy and clay lines start at different $T$. 
Pastoralists almost always move their herds around in response to the changing climatic conditions and a variety of other constraints so as to make the best use of grazing and water resources (Jorritsma, 1979; Ruttan and Borgerhoff Mulder, 1999; Prins, 1999). We believe that, through experience, the pastoralists have a good knowledge of the underlying soil types within the range of migration and that, in the absence of other constraints, their movement strategies take these into consideration. We plan to carry out further research to see whether their movement patterns of the past correlate with the major soil types present in the region.

\section{Conclusion}

Our research shows that the herbage early growth rates on sandy and clay soils are significantly different. The growth rates on sandy soils are greater than that on clayey soils. The largest differences in growth rates are seen at the beginning of the rainy season and this difference gradually becomes constant after about eight weeks into the rainy season. These differences in herbage growth rates can be detected using NOAA-AVHRR imagery. We anticipate that these results can be used to better understand the semi-arid regions and to model the movement behaviour of pastoralists.

\section{Acknowledgements}

Dr Frederick Ouattara, Director of the meteorological office in Ouagadougou, Burkina Faso, made available the NDVI and rainfall data. This study was financially supported by the Netherlands Foundation for Tropical Research (WOTRO) residing under the Netherlands Organization for Scientific Research (NWO) (FLARE programme "Fundamentals of African Rangeland Economies"). We would also like to thank the two reviewers whose comments and suggestions led to a considerable improvement to the paper.

\section{References}

Boulet, R., Leprun, J.C., 1976. Ressources En Sols-Republique De Haute-Volta. Office de la recherche Scientifique et Technique Outre-Mer, France.

Breman, H., de Ridder, N., van Keulen, H., 1991. Evaluation semi-de'taillee. In: Breman, H., de Ridder, N. (Eds.), Manual sur les Paturages des Pays Sahe'liens. Karthala, Paris, pp. $131-219$.

Breman, H., de Wit, C.T., 1983. Rangeland productivity and exploitation in the Sahel. Science 221 (4618), 1341-1347.

Casenave, A., Valentin, C., 1989. Les états de surface de la zone sahélienne. Influence sur l'infiltration. Collection "Didactiques". Orstom, Paris, pp. 229.

Curran, P.J., 1980. Multispectral remote sensing of vegetation amount. Progress in Physical Geography 4, 315-341.

de Boer, W.F., Prins, H.H.T., 1989. Decisions of cattle herdsmen in Burkina Faso and optimal foraging models. Human Ecology 17, 445-464.

D'Herbès, J.M., Valentin, C., 1997. Land surface conditions of the Niamey region: ecological and hydrological implications. Journal of Hydrology 188-189, 18-42.

Govers, G., Poesen, J., 1985. A field-scale study of surface sealing and compaction on loam and sandy loam soils. Part I. Spatial variability of soil surface sealing and crusting. Proceedings Ghent Symposium: assessment of Soil Surface Sealing and Crusting. Ghent, Belgium.

Graef, F., Stahr, K., 2000. Incidence of soil surface crust types in semi-arid Niger. Soil and Tillage Research 55, 213-218.

Heuvelink, G.B.M., 1998. Uncertainty analysis in environmental modelling under a change of spatial scale. Nutrient Cycling in Agroecosystems 50, 255-264.

Holben, B.N., 1986. Characteristics of maximum-value composite images from temporal AVHRR data. International Journal of Remote Sensing 7, 1515.

Hoogmoed, W.B., Stroosnijder, L., 1984. Crust formation on sandy soils in the Sahel. I. Rainfall and infiltration. Soil and Tillage Research 4, 5-23.

Jorritsma, H., 1979. Damergou: Een historische en sociaal ekonomische studie van een landstreek in midden Niger. Ph.D. thesis, Rijksuniversiteit Utrecht/Koninklijk Instituut voor de Tropen, Amsterdam.

Malo, A.R., Nicholson, S.E., 1990. A study of rainfall and vegetation dynamics in the African Sahel using normalized difference vegetation index. Journal of Arid Environments 19, $1-24$.

Morgan, R.P.C., 1986. Soil Erosion and Conservation. Longman Scientific and Technical, Hong Kong.

Mualem, Y., Assouline, S., 1996. Soil sealing, infiltration and runoff. In: Issar, A.S., Resnick, S.D. (Eds.), Runoff, Infiltration and Subsurface Flow of Water in Arid and Semi-arid Regions. Kluwer, London, pp. 131-181.

Nicholson, S.E., Lare, A.R., 1990. A climatonomic description of the surface energy balance in the central sahel. Part II. The evapoclimatonomy submodel. Journal of Applied Meteorology 29, 138-146. 
Pickup, G., Chewings, V.H., Nelson, D.J., 1993. Estimating changes in vegetation cover over time in arid rangelands using Landsat MSS data. Remote Sensing of Environment 43, 243-263.

Prins, H.H.T., 1988. Plant phenology patterns in Lake Manyara National Park. Journal of Biogeography 15, 465480.

Prins, H.H.T., 1999. Comment on Ruttan and Borgerhoff Mulder. Current Anthropology 40, 643-645.

Rietkerk, M., Ketner, P., Burger, J., Hoorens, B., Olff, H., 2000. Multiscale soil and vegetation patchiness along a gradient of herbivore impact in a semi-arid grazing system in West Africa. Plant Ecology 148, 207-224.

Rietkerk, M., Ouedraogo, T., Kumar, L., Sanou, S., van Langevelde, F., Kiema, A., van de Koppel, J., van Andel, J., Hearne, J., Skidmore, A.K., de Ridder, N., Stroosnijder, L., Prins, H.H.T., 2002. Fine-scale spatial distribution of plants and resources on a sandy soil in the Sahel. Plant and Soil, in press.

Ruttan, L.M., Borgerhoff Mulder, M., 1999. Are East African pastoralists truly conservationists. Current Anthropology 40 (5), 621-652.

Tucker, C.J., 1979. Red and photographic infrared linear combinations for monitoring vegetation. Remote Sensing of Environment 8 (2), 127-150.

Tucker, C.J., 1980. A critical review of remote sensing and other methods for non-destructive estimation of standing crop biomass. Grass Forage Science 35, 177-182.

Tucker, C.J., Vanpraet, C.L., Sharman, M.J., van Ittersum, G., 1985. Satellite remote sensing of total herbaceous biomass production in the Senegalese Sahel: 1980-1984. Remote Sensing of Environment 17, 233-249.

Withers, B., Vipond, S., 1974. Irrigation: Design and Practice. Batsford. 